\title{
Dietary Organic and Inorganic Selenium on Liver Glycogen and Lactate, pHu, Color and Drip Loss of Chicken Pectoralis and Gastrocnemius Muscles
}

\author{
Marta del Puerto', Roberto Olivero', Alejandra Terevinto', Ali Saadoun², \\ M. Cristina Cabrera ${ }^{1,2^{*}}$ \\ ${ }^{1}$ Department of Animal Production \& Pastures, Nutrition and Food Quality Laboratory, Faculty of Agronomy, \\ University of the Republic (UDELAR), Montevideo, Uruguay \\ ${ }^{2}$ Physiology \& Nutrition, Faculty of Sciences, University of the Republic (UDELAR), \\ Montevideo, Uruguay \\ Email: *mcab@fagro.edu.uy
}

Received 4 December 2015; accepted 15 January 2016; published 18 January 2016

Copyright (C) 2016 by authors and Scientific Research Publishing Inc.

This work is licensed under the Creative Commons Attribution International License (CC BY).

http://creativecommons.org/licenses/by/4.0/

c) (i) Open Access

\section{Abstract}

The effect of selenium supplementation in finishing broiler diets on meat quality was studied. A corn soya based diet was supplemented with $0.3 \mathrm{ppm}$ of Se from an organic (Seleno methionine; Se-Met) or inorganic source (sodium selenite; Se-Na) and offered to Rossmale chickens from thirty five to fifty two days old. Body weight and feed consumption were recorded during the experimental period. Immediately post sacrifice liver was removed and weight was recorded. The liver glycogen and lactate content was measured. Carcass yield and abdominal fat were determined. At 24 hours post mortem, $\mathrm{pHu}$, colour $\mathrm{L}^{*}, \mathrm{a}^{*}, \mathrm{~b}^{*}, \mathrm{H}^{\circ}, \mathrm{C}^{*}$, and drip loss of the Pectoralis and Gastrocnemius muscles were determined. Se-Met supplementation significantly decreases daily food intake. Se-Na significantly increases liver glycogen and lactate content at 3 minutes post mortem. Se-Met and Se-Na significantly increase pHu as compared to the control diet. Also a Se-Met provoked a darker (lower $\mathrm{L}^{*}$ ) and a redder (higher $\mathrm{a}^{*}$ ) and a decreased tone (lower $\mathrm{H}^{\circ}$ ) in Pectoralis. Se-Met and Se-Na significantly decrease the drip loss in Pectoralis and Gastrocnemius at 24 hours post mortem. We conclude that selenium supplementation decreases food intake and improves meat quality by improving colour and decreasing drip loss, likely by a modulation of reserve of glycogen in liver. The difference among the organic and inorganic sources is not clear and requires further investigation.

\footnotetext{
${ }^{*}$ Corresponding author.
}

How to cite this paper: del Puerto, M., Olivero, R., Terevinto, A., Saadoun, A. and Cabrera, M.C. (2016) Dietary Organic and Inorganic Selenium on Liver Glycogen and Lactate, pHu, Color and Drip Loss of Chicken Pectoralis and Gastrocnemius Muscles. Open Journal of Animal Sciences, 5, 59-67. http://dx.doi.org/10.4236/ojas.2016.61008 


\section{Keywords}

\section{Selenium, pH, Color, Drip Loss, Glycogen, Lactate}

\section{Introduction}

The consumption of poultry meat has increased in recent years in the region and the world due to the high nutritional value, health-effect and functional attributes [1]. However, the production of poultry meat is facing new challenges that make the concept of nutritional, sensory and technological quality. The major problems of poultry meat that occur in the postmortem may be originated in the ante mortem period, when diet is one of the factors that may influence them. In the post mortem, avian muscle suffers important metabolic changes that result in a decrease in the $\mathrm{pH}$ of the meat up to 24 hours. Speed of fall and the final value reached inherit sensory, organoleptic, nutritional and technological quality of poultry meat. The extent and rate of $\mathrm{pH}$ fall hit the most indicative of the sensory quality parameters (color, texture, juiciness, tenderness, flavor, and odor) that affect the acceptability for consumption and promote a series of biochemical processes modifying the suitability of meat for processing and preservation [2]. The rate of $\mathrm{pH}$ decline during the post mortem period and its final value (ultimate $\mathrm{pH}$ ) influence meat attributes (water holding capacity, colour) directly and the technological aptitude for processing indirectly. Oxidative process such as lipid peroxidation and carbonyl formation [3] is the most prevalent factor in conservation and will strongly affect the water holding and color. Glycogen store in the pre mortem is key on the $\mathrm{pH}$ falling. In avian pectoral muscle, a fast $\mathrm{pH}$ drop is associated with protein denaturation in the early post-mortem stages, with the result of poor water retention and less texture [4]. A rapid decrease in the post mortem $\mathrm{pH}$ and a low $\mathrm{pHu}$ reduce the meat quality. However, a limited decrease in $\mathrm{pH}$, and a high $\mathrm{pHu}$ could favour a DFD meat (Dark, firm and dry), resulting in a decrease of the technological capability and product preservation. A strategic dietary modification to modulate the glycogen utilization could improve the meat quality and the properties of this for processing. Also, enhancing the oxidative stability of meat could counteract the oxidation of lipids and proteins, improving the technological characteristics of the meat, the nutritional value and the acceptation by the consumers. Among the dietary factors as antioxidants, selenium has many properties, because of its dual role as a cofactor of the antioxidant enzyme GPx [5] whose antioxidant effect has been well showed in poultry [6] and the interesting effect as insulin-like [7] which could modify the glycogenstores and the glycolysis observed in rats [8]. According this role in muscle, a hypothesis that the Se supplementation could modulate the glycogen metabolism in poultry could be raised. However the assimilative capacity and the effects on the animal of the dietary selenium depend largely on the source used, either organic or selenomethionine or inorganic such as sodium selenite [9]-[11]. Selenium in animal diets is supplemented primarily as inorganic sodium selenite or sodium selenate, but there is increasing interest in the use of organic forms, such as selenomethionineas supplemental sources of Se [12]. Diets supplemented with either sodium selenite or Se-enriched yeast have shown that organic selenium is deposited more effectively in broiler breast muscles than inorganic selenium [13], and improves the color meat [14] during retail. Mueller et al. [15] showed that the chemical form of selenium, selenite or selenate also has different insulin mimetic properties of the trace element in rats. In our knowledge, the effect of selenium supplementation on the liver glycogen stores has not been studied in poultry. So the aim of this study was to evaluate the effect of supplemented finishing broiler diet with organic and inorganic selenium on the animal growth, liver glycogen and lactate content, and $\mathrm{pHu}$, color and drip loss in the Pectoralis and Gastrocnemius muscles at 24 hours post mortem.

\section{Material and Methods}

\subsection{Animals, Management and Diets}

The animal care and handling were approved by the Honorary Committee on Experimental Animals of the University of the Republic, Montevideo, Uruguay (CHEA) before the experiments started. The trial was conducted at the Faculty of Agronomy of the University of the Republic (UDELAR, Montevideo, Uruguay), following the human animal care and handling procedures, according to the accepted protocol. One-day-old male Ross birds obtained from a commercial hatchery were reared until thirty-five days on a floor pen with wood shavings, in a 
climate-controlled room with a photoperiod of 23 hours of light. They were fed ad libitum with a commercial corn-soya diet (219 g/kg CP; $13.35 \mathrm{MJ} / \mathrm{kg}$ of ME). Fresh water was given ad libitum. At thirty-five day, ninety birds were selected by weight and health appearance and assigned randomly into three groups of thirty birds each located in ten experimental pens $(90 \mathrm{~cm} \times 90 \mathrm{~cm}$ each one) with wood shavings as litter. Each pen located three birds. Birds were fed, ad libitum, with one of the experimental diets until sacrifice. A corn-soya based diet was formulated to meet the nutrient requirements for finishing male broilers following INRA [16] and Larbier \& Leclercq [17] and was considered the basal diet (Table 1). The other two diets were supplemented with Se from an organic source (0.3 ppm Se, as selenomethionine, SeMet) and an inorganic source (0.3 ppm Se, as sodium selenite, SeNa). All diets were iso-protein and iso-energetic (200 g/kg CP, $13.10 \mathrm{MJ} / \mathrm{kg}$ of ME). Dry matter, crude protein, crude fibre and selenium content analyses of feed were carried out according to AOAC methods [18] and Ramos et al. [19].

\subsection{Animal Parameters}

Individual body weight at 35 and at 52 days of age was determined, and weight gain for the experimental period was estimated as the difference between the two measures. Daily food consumption and conversion efficiency ( $\mathrm{kg}$ feed $/ \mathrm{kg}$ gain) were also calculated. At fifty-two days old all the birds were sacrificed in an experimental abattoir. Pre-harvest handling and transportation (transportation time was 3 minutes) were in accordance with good animal welfare practices. Slaughtering procedures followed the CHEA accepted protocols. At 52 days, all the birds were slaughtered after fasting for 4 hours according to standards established by CHEA, making the sacrifice by cutting the jugular vein until total bleeding $(3 \mathrm{~min}$ ) to cause the least possible stress to the animal. Im-

Table 1. Chemical composition of experimental diets $(\mathrm{g} / \mathrm{kg})$.

\begin{tabular}{|c|c|c|c|}
\hline & \multicolumn{3}{|c|}{ Experimental diets } \\
\hline & Control & Se-Met (0.3 ppm Se) & Se-Na (0.3 ppm Se) \\
\hline Ground corn & 600 & 600 & 600 \\
\hline Soybean meal & 325 & 325 & 325 \\
\hline Meat and bone meal & 42 & 42 & 42 \\
\hline Calcium carbonate & 10 & 10 & 10 \\
\hline Dicalcium phosphate & 8 & 8 & 8 \\
\hline Sunflower Oil & 5 & 5 & 5 \\
\hline $\mathrm{NaCl}$ & 3 & 3 & 3 \\
\hline L-Lysine.HCl & 2.5 & 2.5 & 2.5 \\
\hline DL-Methionine & 1 & 1 & 1 \\
\hline \multirow[t]{2}{*}{$\operatorname{Premix}^{(*)}$} & 2.5 & 2.5 & 2.5 \\
\hline & \multicolumn{3}{|c|}{ Nutrient content of experimental diets } \\
\hline Crude Protein, (g/kg) ${ }^{(* *)}$ & 200 & 200 & 200 \\
\hline Metabolizable Energy, (MJ/kg) & 13.10 & 13.10 & 13.10 \\
\hline Crude Fiber, $(\mathrm{g} / \mathrm{kg})^{(* *)}$ & 37 & 37 & 37 \\
\hline $\mathrm{Ca},(\mathrm{g} / \mathrm{kg})$ & 12 & 12 & 12 \\
\hline $\mathrm{P},(\mathrm{g} / \mathrm{kg})$ & 4.2 & 4.2 & 4.2 \\
\hline Se, $(p p m)^{(* *)}$ & 0.01 & 0.29 & 0.30 \\
\hline
\end{tabular}

${ }^{(*)}$ Broiler mineral and vitamin premix. Provided (per 1,5 kilograms of diet): 12.000.000 U.I. of vitamin A, 2.000.000 UI of vitamin D3, 25.000 U.I of vitamin E, $7.6 \mathrm{~g}$ of vitamin K, $5 \mathrm{~g}$ of vitamin B2, $10 \mathrm{~g}$ of calcium D pantothenate, $30 \mathrm{~g}$ of niacin, $0.5 \mathrm{~g}$ of folic acid, $13 \mathrm{mg}$ of vitamin B12, $500 \mathrm{~g}$ of choline chloride, $0.5 \mathrm{~g}$ of vitamin B1, $1 \mathrm{~g}$ of vitamin B6, $90 \mathrm{~g}$ of Mn, $35 \mathrm{~g}$ of $\mathrm{Zn}, 25 \mathrm{~g}$ of Fe, $2 \mathrm{~g}$ of Cu, $2 \mathrm{~g}$ of I, $0.1 \mathrm{~g}$ of Co and $0.1 \mathrm{~g}$ of Se. (**) Analytical values. 
mediately after exsanguination, the liver was extracted $(3 \mathrm{~min})$ and the gallbladder was removed. The total fresh weight was measured followed by immediate storage at $-80^{\circ} \mathrm{C}$ until analysis. Eviscerated carcass weight was determined following slaughter, evisceration and post chilling. At 24 hours post mortem followed for a refrigeration at $4^{\circ} \mathrm{C}$, the weight of abdominal fat was determined [20].

\subsection{Meat Quality Parameters}

The $\mathrm{pH}$ was determined at 24 hours post mortem (maintained at $4^{\circ} \mathrm{C}$ ) in the Pectoralis and Gastrocnemius muscles from both sides, using a penetration $\mathrm{pH}$ meter LT Lutron $\mathrm{pH}-201$. Meat colour was determined (after 30 min bloom time) using the CIELAB method $\mathrm{L}^{*}, \mathrm{a}^{*} \mathrm{~b}^{*}$ at 24 hours post mortem (at $4^{\circ} \mathrm{C}$ ) in the Pectoralis and Gastrocnemius muscles from both sides (two readings on each) using a Minolta Lab CR-10 colorimeter. Measurement conditions were with illuminant $\mathrm{D}_{65}$, an observation angle of $10^{\circ}$ and an aperture size of 0.31 inches. The chroma $\left(C^{*}=\sqrt{a^{* 2}+b^{* 2}}\right)$ and hue $\left(H^{\circ}=\arctan b^{*} / a^{*}\right)$ were also calculated [21]. Water drip loss was determined by the weight difference in $2.5 \mathrm{~g}$ of Pectoralis and Gastrocnemius muscles samples at 24 hours post mortem from both sides [22].

\subsection{Glycogen and Lactate Content in Liver}

Glycogen and lactate content were measured 3 min post mortem for the liver. Briefly, an $8 \mathrm{~g}$ meat sample was homogenized and extracted with $8 \mathrm{ml}$ of $\mathrm{HCl}$ acid $(4 \mathrm{~N})$ for 2 hours at $100^{\circ} \mathrm{C}$, filtered and neutralized by adding $\mathrm{NaOH}(4 \mathrm{~N})$ until pH reached 6.5 - 7 [23]. Glycogen was determined as glucose total equivalents following Bergmeyer et al. [24] using colorimetric diagnostic kits (1001201, Spinreact, Spain) and expressed as mg glucose $/ \mathrm{kg}$ fresh meat. Lactate was assayed in the same hydrolysed slurry using commercially available enzymatic colorimetric diagnostic kits (LO-POD; 1001330; Spinreact, Spain) and expressed as mg lactate/kg fresh meat.

\subsection{Statistical Analysis}

The data of body weight, feed consumption, body weight gain, conversion efficiency, liver glycogen and lactate content, and pHu, color and drip loss for Pectoralis and Gastrocnemius muscles are reported as mean \pm standard error of the media in the three experimental treatment. The effect of selenium supplementation on the performance parameters and liver glycogen and lactate content was analyzed by one-way ANOVA and post hoc Tukey-Kramer Test. To determine the main effects of the supplemented selenium and muscle on the $\mathrm{pH}$, color and drip loss an ANOVA GLM was used followed by Tukey-Kramer Test. The level of significance was established at $\mathrm{P}<0.05$, and the software used was the NCSS, 2007 (NCSS, 329 North 1000 East, Kaysville, UT 84037).

\section{Results and Discussion}

\subsection{Animal Parameters}

Selenium supplementation did not affected final body weight, average daily gain or conversion efficiency (g gain/g feed) of birds al 52 days old, but a significantly decrease in average daily food intake was observed only for poultry supplemented with 0.3 of Se as Se-Met (Table 2). This result was also observed by [25] and [26] who found a significant $(\mathrm{P}<0.05)$ improvement in food conversion ratio in broilers fed with organic Se at 0.20 $0.25 \mathrm{mg} / \mathrm{kg}$ resulting from lower feed intake while maintaining the same live weight gain.In the present work, gain: feed ratio was not different significantly between the diets. Further studies are necessary to explain these effects on the appetite poultry. Bunk and Combs [27] has shown that selenium modify the appetite in seleniumdeficient poultry increasing the food intake. However others authors [28]-[30] report an increase in feed intake and in body weight in chicken but not associated to a deficiency in selenium, while Payne and Southern [13] report any effect to the selenium supplementation on animal growth.

\subsection{Liver Glycogen and Lactate Content}

An significantly $(\mathrm{P}<0.05)$ increase in glycogen and lactate content in liver al 3 minutes post sacrifice was observed with the Se-Na supplementation (Table 3). Selenium is associated to a higher restoration of glycogen levels in liver after an exercise in rats [31] but it depends on the source and levels of supplementation. In this work we observed also an effect on the lactate levels only with Se-Na supplementation. Lactate level are associated to 
Table 2. Effect of selenium supplementation $(0.3 \mathrm{ppm})$ as selenomethionine (Se-Met) or sodium selenite (Se-Na) in a broiler finishing diet (35 - 52 days old) on animal performance parameters: final body weight (g at 52 days old); average daily feed intake (g/d), average daily gain (g/d), conversion efficiency ( $\mathrm{g}$ gain/g feed) during the period 35 - 52 days; and weight of liver and abdominal fat (g) and as a percentage of body weight at 52 days old and carcass yield (\%).

\begin{tabular}{cccccc}
\hline & \multicolumn{3}{c}{ Experimental diets } & P \\
\hline Items & Control & Se-Met & Se-Na & 0.89 \\
Final body weight, $\mathbf{g}$ & $3770 \pm 106$ & $3837 \pm 95$ & $3792 \pm 103$ & 0.001 \\
Average daily feed intake, g/d & $148.0 \pm 1.4 \mathbf{~ a ~}$ & $140.5 \pm 1.6 \mathbf{b}$ & $150.5 \pm 1.8 \mathbf{a}$ & $75.7 \pm 2.9$ & 0.80 \\
Average daily gain, g/d & $74.8 \pm 2.7$ & $77.4 \pm 2.6$ & $0.50 \pm 0.02$ & 0.08 \\
Gain: Feed, g/g & $0.50 \pm 0.02$ & $0.55 \pm 0.02$ & $54.4 \pm 1.3$ & 0.62 \\
Liver weight, g & $56.5 \pm 1.9$ & $57.4 \pm 3.1$ & $1.65 \pm 0.03$ & 0.62 \\
Liver weight, as \% body weight & $1.58 \pm 0.04$ & $1.59 \pm 0.08$ & $47.5 \pm 2.9$ & 0.28 \\
Abdominal fat, g & $52.0 \pm 4.9$ & $41.8 \pm 5.4$ & $1.44 \pm 0.07$ & 0.20 \\
Abdominal fat, as \% body weight & $1.46 \pm 0.14$ & $1.17 \pm 0.15$ & $77.6 \pm 1.0$ & 0.36 \\
\hline
\end{tabular}

Data represent mean \pm SEM of $n=10$ (3 birds by pen). Differences between diets were analyzed by ANOVA one way followed by a Tukey-Kramer Test $(\mathrm{P}<0.05)$. Different lowercase in the row means differences between diets. A carcass yield calculated as eviscerated weight divided by final body weight times 100 .

Table 3. Effect of selenium supplementation $(0.3 \mathrm{ppm})$ as selenomethionine (Se-Met) or sodium selenite (Se-Na) in a broiler finishing diet (35 - 52 days old) on liver glycogen content, as g glucose/kg fresh meat, and lactate content, as g lactate/kg fresh meat, at 3 minutes post slaughter.

\begin{tabular}{|c|c|c|}
\hline Diets & Glycogen (g/kg fresh meat) & Lactate (g/kg fresh meat) \\
\hline Control & $6.20 \pm 0.19 \mathbf{b}$ & $1.09 \pm 0.16 \mathbf{b}$ \\
\hline Se-Met & $6.94 \pm 0.16 \mathbf{a b}$ & $1.40 \pm 0.10 \mathbf{a b}$ \\
\hline Se-Na & $7.04 \pm 0.34 \mathbf{a}$ & $1.54 \pm 0.07 \mathbf{a}$ \\
\hline $\mathbf{P}$ & 0.05 & 0.04 \\
\hline
\end{tabular}

Data are mean SEM of $\mathrm{n}=18$.Values followed by different lowercase letters in each column means significant differences between diets by one-way ANOVA followed by a Tukey-Kramer Test $(\mathrm{P}<0.05)$.

increased exercise and it was show that selenium supplementation could increase the antioxidant activity in muscle reducing accumulation of lactate and free radicals [32]. Lisuka et al. [33] observed a hypoglycemic effect of selenium supplementation and that might be due to the acceleration of glucose metabolism and the inhibition of glucose synthesis in the liver, suggesting a decrease in a source of precursor supply for the gluconeogenesis. The augmentation observed in this work could be due to an increase rate of glycolysis or a diminished sortie from liver to blood and muscle. More research is necessary to highlight this point.

\subsection{Meat Quality Parameters}

Selenium supplementation significantly modified the pHu in Pectoralis and Gastrocnemius muscles (Figure 1) arising levels of pHu near values of 5.9 - 6.0. These values are consistent with the values reported by Duclos et al. [34] and could indicate normal glycolysis [35].

An effect on the colour parameters as $\mathrm{L}^{*}, \mathrm{a}^{*}$ and hue was observed for the diet supplemented with organic selenium (Table 4). This effect was significant only in Pectoralis muscle. Diet with Se-Met as selenium source provoked a darker and a redder meat than control and diet with Se-Na. Se-Met source provoked a lower tone also in Pectoralis. The colour of fresh meat is a very important factor in the buying decision made by the consumer, and consumers often see this colour as an indicator of the freshness and overall quality of the meat [36] [37]. Colour is usually expressed by three components: brightness, $L^{*}$; redness, $a^{*}$; and yellowness, $b^{*}$ and according to the data obtained in our work for the pectoral muscle, selenium organic decrease the component brightness and tone and increase redness at 24 hours post mortem $(\mathrm{P}>0.05)$. The values found for redness, $\mathrm{a}^{*}$ could be explained by a less degradation of myoglobin during the establishment of rigor mortis. The $a^{*}$ values for the Pectoralis muscle for Se-Met supplemented diet is higher than values reported by Fletcher et al. [36], 


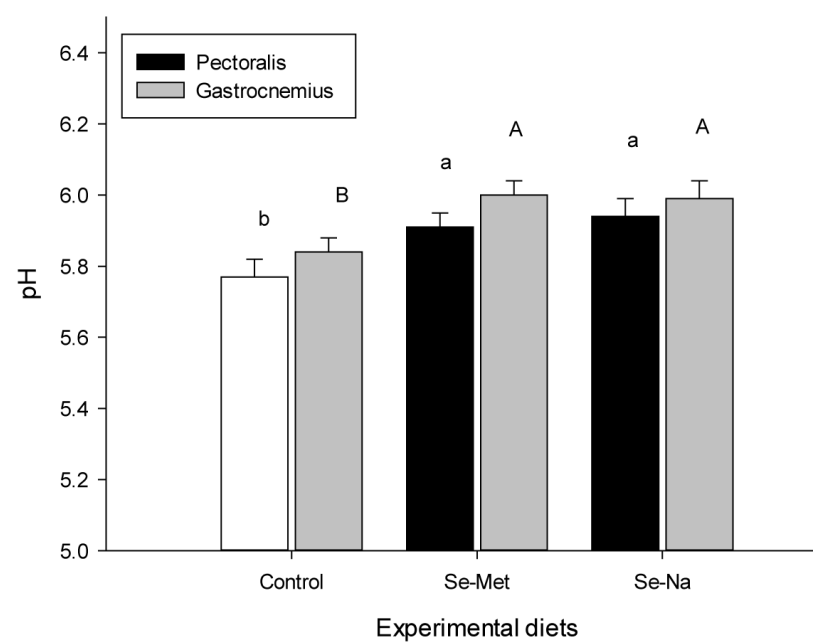

Figure 1. Effect of selenium supplementation $(0.3 \mathrm{ppm})$ as selenomethionine (Se-Met) or sodium selenite (Se-Na) in a broiler finishing diet (35 - 52 days old) on the $\mathrm{pHu}$ in muscles Pectoralis (PM) and Gastrocnemius (GM) at 24 hours post mortem. Data are the mean \pm SEM for $\mathrm{n}=18$. The $\mathrm{pH}$ measurements for each bird were performed on both sides for both muscles. The main effects for diets and muscles were analyzed by ANOVA with a GLM procedure followed by the post hoc Tukey-Kramer test for comparison $(\mathrm{P}<0.05)$. Bar with different lowercase $(\mathrm{PM})$ or uppercase (GM) means significant different by one-way ANOVA and Tukey-Kramer test $(\mathrm{P}>0.05)$. Main effects: Diets, $\mathrm{P}<0.001$, Se-Met, Se-Na $>$ Control; Muscles, $\mathrm{P}<0.02$, GM $>$ PM.

Table 4. Effect of selenium supplementation $(0.3 \mathrm{ppm})$ as selenomethionine (Se-Met) or sodium selenite (Se-Na) in a broiler finishing diet (35 - 52 days old) on the color, measured as $\mathrm{L}^{*}, \mathrm{a}^{*}, \mathrm{~b}^{*}$ (CIELAB method) and on color tone measured as angle hue $\left(H^{\circ}\right)$ and the color saturation measured as chroma $\left(C^{*}\right)$ in muscles Pectoralis $(P M)$ and Gastrocnemius $(G M)$ at 24 hours post mortem.

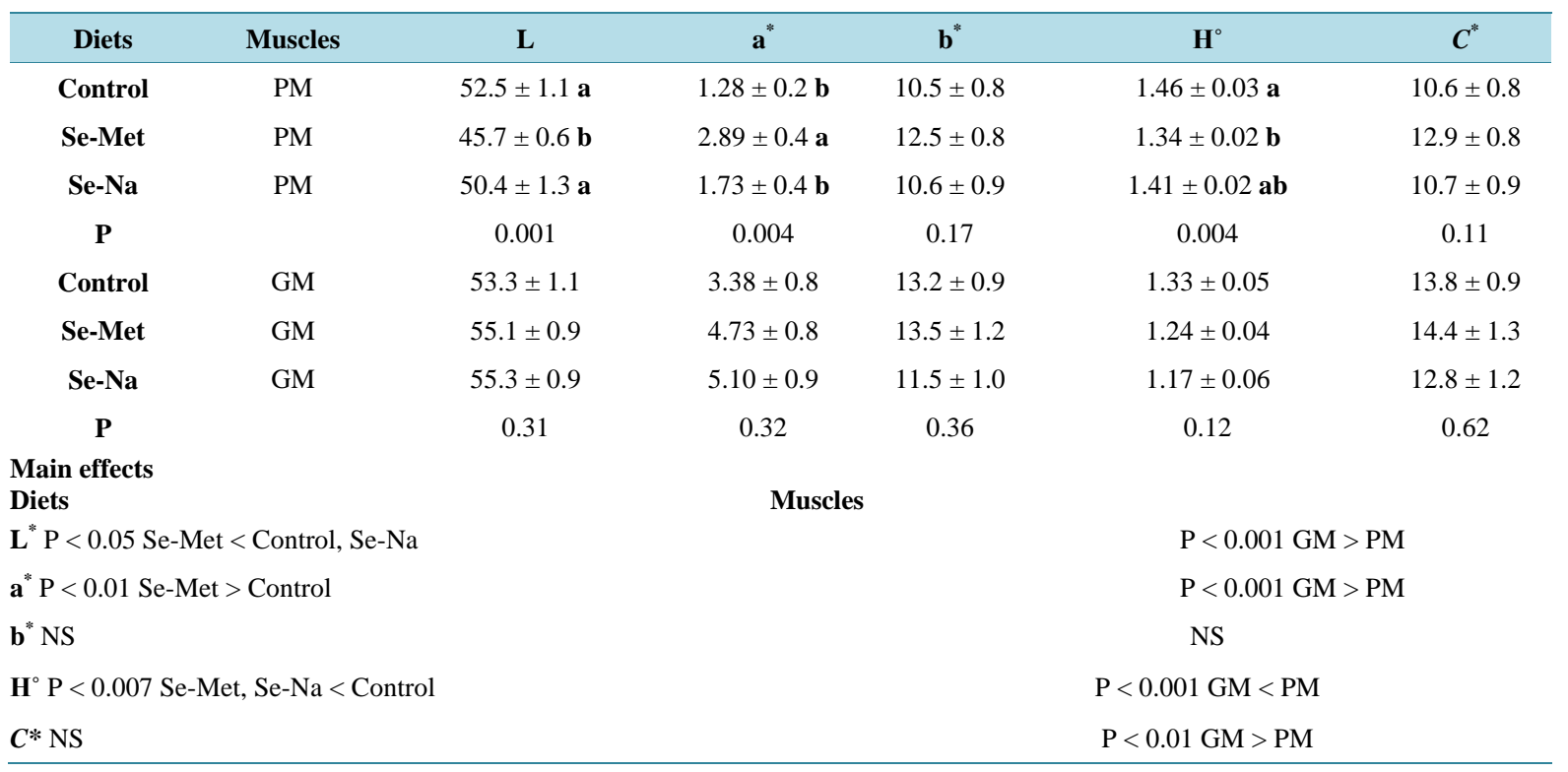

Data are mean \pm SEM of $n=18$. The main effects were analyzed by ANOVA with a GLM procedure and the Tukey-Kramer Test for diets and muscles $(\mathrm{P}>0.05)$. Values followed by different lowercase letters in each column indicate significant differences between diets for each color parameter in each muscle by one-way ANOVA followed by a Tukey-Kramer Test $(\mathrm{P}<0.05)$.

$a^{*}=1.7-2.2$ at 24 hours post slaughter. No effect was found for the yellowish-green colour, determined by the variable $b^{*}$. In the study of the proportion of red and yellow through the Hue parameter (Table 4), we note a decrease of hue only in the Pectoralis muscle when selenium organics was included.

Drip loss was significantly reduced by selenium supplementation compared to the control diet (Table 5). This 
Table 5. Effect of selenium supplementation $(0.3 \mathrm{ppm})$ as seleno methionine (Se-Met) or sodium selenite (Se-Na)in a broiler finishing diet (35 - 52 days old) on drip loss (\%)in muscles Pectoralis (PM) and Gastrocnemius (GM) at 24 hours post mortem.

\begin{tabular}{|c|c|c|c|c|}
\hline \multirow[b]{2}{*}{ Muscles } & \multicolumn{4}{|c|}{ Experimental diets } \\
\hline & Control & Se-Met & Se-Na & $\mathrm{P}$ \\
\hline GM & $2.09 \pm 0.25 \mathbf{a}$ & $1.28 \pm 0.11 \mathbf{b}$ & $1.22 \pm 0.22 \mathbf{b}$ & 0.05 \\
\hline PM & $1.73 \pm 0.20 \mathrm{a}$ & $1.29 \pm 0.07 \mathbf{b}$ & $1.22 \pm 0.10 \mathbf{b}$ & 0.05 \\
\hline $\begin{array}{l}\text { Main effects } \\
\text { Diet } P<0.01\end{array}$ & \multicolumn{2}{|c|}{ Muscle NS } & & \\
\hline
\end{tabular}

Data are mean SEM of $n=18$. The main effects were analyzed by ANOVA with a GLM procedure and the Tukey-Kramer Test for diets and muscles $(\mathrm{P}>0.05)$. Values followed by different lowercase letters in each row indicate significant differences between diets in each muscle by one-way ANOVA followed by a Tukey-Kramer test $(\mathrm{P}<0.05)$. NS = no significant.

effect was observed in both muscles, Pectoralis and Gastrocnemius al 24 hours post mortem. This effect was previously observed in poultry by [25] and [14].

The first one showed that a positive difference was found for the organic source on minimizing water loss in breast. In turkeys, Mikulsky et al. [38] reported a similar effect of both sources on the drip loss. In the present work we have not any differences between the sources and both were effectives for this parameter. Also, we found that this effect was in both muscles studied whereas the other works studied only the pectoral muscle. Beyond the role of selenium in the protection of cells from damage, the dietary selenium source seems improve meat quality, with particular reference to protect muscle of excessive tissue water loss [38]. It seems likely that a stabilizing effect of Se is also associated with maintaining muscle membrane integrity. The drip loss affects principally the marketing pieces of chickens, and processed products and is coming a substantial economic problem [39] and it is estimated that drip loss can account for more than $3 \%$ of the total yield of cut-up chicken. Excessive cellular damage resulting from oxidation may be the cause of drip loss [26]. In this sense, Edens [40] showed that drip loss was decreased when organic Se was fed to broilers. Using a model system based on red blood cell membrane stability Edens [40] confirmed a membrane-stabilizing effect of organic Se. Running studies in our laboratory about the lipids and protein oxidation and GPx activity in meat from poultry receiving selenium supplementation with inorganic and organic sources could be explain this findings.

\section{Conclusion}

We studied the effects of selenium supplementation in a finishing broiler diet on the meat quality and animal parameters. We observed that Se-Met supplementation significantly decreases daily food intake whereas Se-Na significantly increases liver glycogen and lactate content at 3 minutes post mortem. Se-Met and Se-Na significantly increase pHu compared to the control diet. Also Se-Met in diet provoked a darker (lower L ${ }^{*}$ ) and a redder (higher $\mathrm{a}^{*}$ ) and a decreased tone (lower $\mathrm{H}^{\circ}$ ) in Pectoralis. Se-Met and Se-Na significantly decrease the drip loss in Pectoralis and Gastrocnemius at 24 hours post mortem. We conclude that selenium supplementation decreases food intake and improves meat quality by improving color and decreasing drip loss, likely by a modulation of reserve of glycogen in liver. The difference among the organic and inorganic sources is not clear and requires further investigation.

\section{Acknowledgements}

We appreciate to Mrs. Carmen Figarola and Mr. Pablo Flaskbard by the technical assistance for this investigation.

\section{References}

[1] Grashorn, M.A. (2011) Functionality of Poultry Meat. Journal of Applied Poultry Research, 16, 99-106. http://dx.doi.org/10.1093/japr/16.1.99

[2] Woefel, R.L., Owens, C.M., Hirscheler, E.M., Martinez-Dawson, R. and Sams, A.R. (2002). The Characterization and Incidence of Pale, Soft, and Exudative Broiler Meat in Commercial Processing Plant. Poultry Science, 81, 579-584. http://dx.doi.org/10.1093/ps/81.4.579 
[3] Soyer, A., Özalp, B., Dalmış U. and Bilgin, V. (2010) Effects of Freezing Temperature and Duration of Frozen Storage on Lipid and protein oxidation in Chicken Meat. Food Chemistry, 120, 1025-1030.

[4] Barbut, S., Sosnicki, A.A., Lonergan, S.M., Knapp, T., Ciobanu, D.C., Gatcliffe, L.J., Huff-Lonergan, E. and Wilson, E.W. (2008) Progress in Reducing the Pale, Soft and Exudative (PSE) Problem in Pork and Poultry Meat. Meat Science, 79, 46-63. http://dx.doi.org/10.1016/j.meatsci.2007.07.031

[5] Arthur, J.R.I. (2000) The Glutathione Peroxidases. Cellular Molecular Life Science, 57, 1825-1835.

[6] Pedrero, Z. and Madrid, Y. (2009) Novel Approaches for Selenium Speciation in Foodstuffs and Biological Specimens: A Review. Analytical Chimica Acta, 634, 135-152. http://dx.doi.org/10.1016/j.aca.2008.12.026

[7] Stapleton, S.R. (2000) Selenium: An Insulin Mimetic. Cellular and molecular life Science, 57, 1874-1879. http://dx.doi.org/10.1007/PL00000669

[8] Zhou, J., Huang, K. and Gen Lei, X. (2013) Selenium and Diabetes-Evidence from Animal Studies. Free Radical Biology and Medicine, 65, 1548-1556.

[9] Beilstein, M.A. and Whanger, P.D. (1986) Chemicals Forms of Selenium in Rat Tissues after Administration of Selenite or Seleniomethionine. The Journal of Nutrition, 116, 1711-1719.

[10] Sevcikova, S., Skrivan, M., Dlougha, G. and Moucky, M. (2006) The Effect of Selenium Source on the Performance and Meat Quality of Broiler Chickens. Czech Journal of Animal Science, 51, 449-457.

[11] Juniper, D.T., Phipps, R.H., Ramos-Morales, E., and Bertin, G. (2008) Effect of Dietary Supplementation with Selenium-Enriched Yeast or Sodium Selenite on Selenium Tissue Distribution and Meat Quality in Beef Cattle. Journal of Animal Science, 86, 3100-3109. http://dx.doi.org/10.2527/jas.2007-0595

[12] Rayman, M. (2004) Review Article. The Use of High-Selenium Yeast to Raise Selenium Status: How Does It Measure up? British Journal of Nutrition, 92, 557-573. http://dx.doi.org/10.1079/BJN20041251

[13] Payne, R.L. and Southern, L.L. (2005) Comparison of Inorganic and Organic Selenium Sources for Broilers. Poultry Science, 84, 898-902. http://dx.doi.org/10.1093/ps/84.6.898

[14] Downs, K.M., Hess, J.B. and Bilgili, S.F. (2000) Selenium Source Effect on Broiler Carcass Characteristics, Meat Quality and Drip Loss. Journal of Applied Animal Research, 18, 61-72. http://dx.doi.org/10.1080/09712119.2000.9706324

[15] Mueller, A.S., Pallauf, J. and Rafael, J. (2003) The Chemical Form of Selenium Affects Insulinomimetic Properties of the Trace Element: Investigations in Type II Diabetic dbdb Mice. Journal of Nutritional Biochemistry, 14, 637-647. http://dx.doi.org/10.1016/j.jnutbio.2003.08.001

[16] INRA (1989) L’Alimentation des animaux monogastriques: Porc, lapin, volailles, 2 éme edition. Editions Quae, 282 p.

[17] Larbier, M. and Leclercq, B. (1992) Nutrition et alimentation des volailles. Editions Quae, 355 p.

[18] AOAC (2005) International, Official Methods of Analysis. 18th Edition, Association of Official Analytical Chemists, Washington DC, USA.

[19] Ramos, A., Cabrera, M.C. and Saadoun, A. (2012) Bioaccessibility of Se, Cu, Zn, Mn and Fe, and Heme Iron Content in Unaged and Aged Meat of Hereford and Braford Steers Fed Pasture. Meat Science, 91, 116-124. http://dx.doi.org/10.1016/j.meatsci.2012.01.001

[20] Delpech, P. and Ricard, F. (1965) Relation entre les depots adipeux visceraux et les lipides corporels chez le poulet. Annales de Zootechnie, 14, 181-189. http://dx.doi.org/10.1051/animres:19650205

[21] Little, A.C. (1975) Research Note off on a Tangent. Journal of Food Science, 40, 410-411. http://dx.doi.org/10.1111/j.1365-2621.1975.tb02213.x

[22] Penny, I.J. (1967) The Influence of $\mathrm{pH}$ and Temperature on the Properties of Myosin. Biochemical Journal, 104, 609-615. http://dx.doi.org/10.1042/bj1040609

[23] Lowry, O.H. and Passoneau, J.V. (1973) A Flexible System of Enzymatic Analysis. Academic Press, New York.

[24] Bergmeyer, H.V. and Bernt, E. (1974) Amylo-1,6-glycosidase for the Determination of Glycogen. In: Bergmeyer, H.V., Ed., Methods of Enzymatic Analysis, Vol. 3, Academic Press, New York, London, 1127.

[25] Choct, M., Naylor, A.J. and Reinke, N. (2004) Selenium Supplementation Affects Broiler Growth Performance, Meat Yield and Feather Coverage. British Poultry Science, 45, 5. http://dx.doi.org/10.1080/00071660400006495

[26] Zhou, X. and Wang, Y. (2011) Influence of Dietary Nano Elemental Selenium on Growth Performance, Tissue Selenium Distribution, Meat Quality, and Glutathione Peroxidase Activity in Guangxi Yellow Chicken. Poultry Science, 90, 680-686. http://dx.doi.org/10.3382/ps.2010-00977

[27] Bunk, M.J. and Combs Jr., G.F. (1980) Effect of Selenium on Appetite in the Selenium-Deficient Chick. Journal of Nutrition, 110, 743-749.

[28] Cantor, A.H., Scott, M.L. and Noguchi, T. (1975) Biological Availability of Selenium in Feedstuffs and Selenium 
Compounds for Prevention of Exudative Diathesis in Chicks. Journal of Nutrition, 105, 96-105.

[29] Cantor, A.H., Scott, M.L. and Noguchi, T. (1975) Efficacy of Selenium in Selenium Compounds and Feedstuffs for Prevention of Pancreatic Fibrosis in Chicks. Journal of Nutrition, 105, 106-111.

[30] Cantor, A.H., Moorehead, P.D. and Musser, M.A. (1982) Comparative Effects of Sodium Selenite and Selenomethionine upon Nutritional Muscular Dystrophy, Selenium-Dependent Glutathione Peroxidase, and Tissue Selenium Concentrations of Turkey Poults. Poultry Science, 61, 478-484. http://dx.doi.org/10.3382/ps.0610478

[31] Akil, M., Bicer, M., Kilic, M., Cihat Avunduk, M., Mogulkoc, R. and Baltac, A.K. (2011) Effect of Intraperitoneal Selenium Administration on Liver Glycogen Levels in Rats Subjected to Acute Forced Swimming. Biological Trace Element Research, 139, 341-346. http://dx.doi.org/10.1007/s12011-010-8667-4

[32] Akil, M., Gurbuz, U., Bicer, M., Sivrikaya, A., Mogulkoc, R. and Baltaci, A.K.(2010) Effect of Selenium Supplementation on Lipid Peroxidation, Antioxidant Enzymes, and Lactate Levels in Rats Immediately After Acute Swimming Exercise. Biological Trace Element Research, 142, 651-659. http://dx.doi.org/10.1007/s12011-010-8785-z

[33] Iizuka, Y., Sakurai, E., Maeda, K. and Hikichi, N. (1993) Effects of Selenium on the Glycolysis and Gluconeogenesis System in Rat Liver. Yakugaku Zasshi, 113, 525-531.

[34] Duclos, M.J., Berri, C. and Le Bihan-Duval, E. (2007) Muscle Growth and Meat Quality. Journal Applied Poultry Research, 16, 107-112. http://dx.doi.org/10.1093/japr/16.1.107

[35] Santè, V., Fernandez, X., Monin, G. and Renou, J.P. (2001) Nouvelles Methodes des Mesures de la Qualite des Viandes de Volailles INRA. Productions Animales, 14, 247-254.

[36] Fletcher, D.L. (1999) Colour Variation in Commercial Packed Broiler Breast Fillet. Journal of Applied Poultry Research, 8, 67-69. http://dx.doi.org/10.1093/japr/8.1.67

[37] El Rammouz, R., Babilé, R. and Fernandez, X. (2004) Effect of Ultimate pH on the Physicochemical and Biochemical Characteristics of Turkey Breast Muscle Showing Normal Rate of Post Mortem pH Fall. Poutry Science, 83, 1750-1757. http://dx.doi.org/10.1093/ps/83.10.1750

[38] Mikulski, D., Jankowski, J., Zduńczyk, Z., Wróblewska, M., Sartowska, K. and Majewska, T. (2009) The Effect of Selenium Source on performance, Carcass Traits, Oxidative Status of the Organism, and Meat Quality of Turkeys. Journal of Animal and Feed Sciences, 18, 518-530.

[39] Boutten, B. (2003) Advances in Poultry Meat Processing Technology. XVIth European Symposium on the Quality of Poultry Meat, Saint-Brieux, France, August 2003, 14-24.

[40] Edens, F.W. (2001) Involvement of Sel-Plex in Physiological Stability and Performance of Broiler Chickens. In: Lyons, T.P. and Jacques, T.A., Eds., Biotechnology in the Feed Industry: Proceedings of Alltech's 17th Annual Symposium, Nottingham University Press, Nottingham, UK, 349-376. 